CONF-9510144--1

UCRL-JC-121248

PREPRINT

\title{
Autoignition Chemistry of the Hexane Isomers: An Experimental nd Kinetic Modeling Sudy
}

\author{
H.J. Curran \\ P. Gaffuri \\ W.J. Pitz \\ C.K. Westbrook \\ W.R. Leppard
}

This paper was prepared for submittal to the

1995 SAE International Fuels and Lubricants Meeting and Exposition

Toronto, Canada

October 16-19, 1995

June 1995

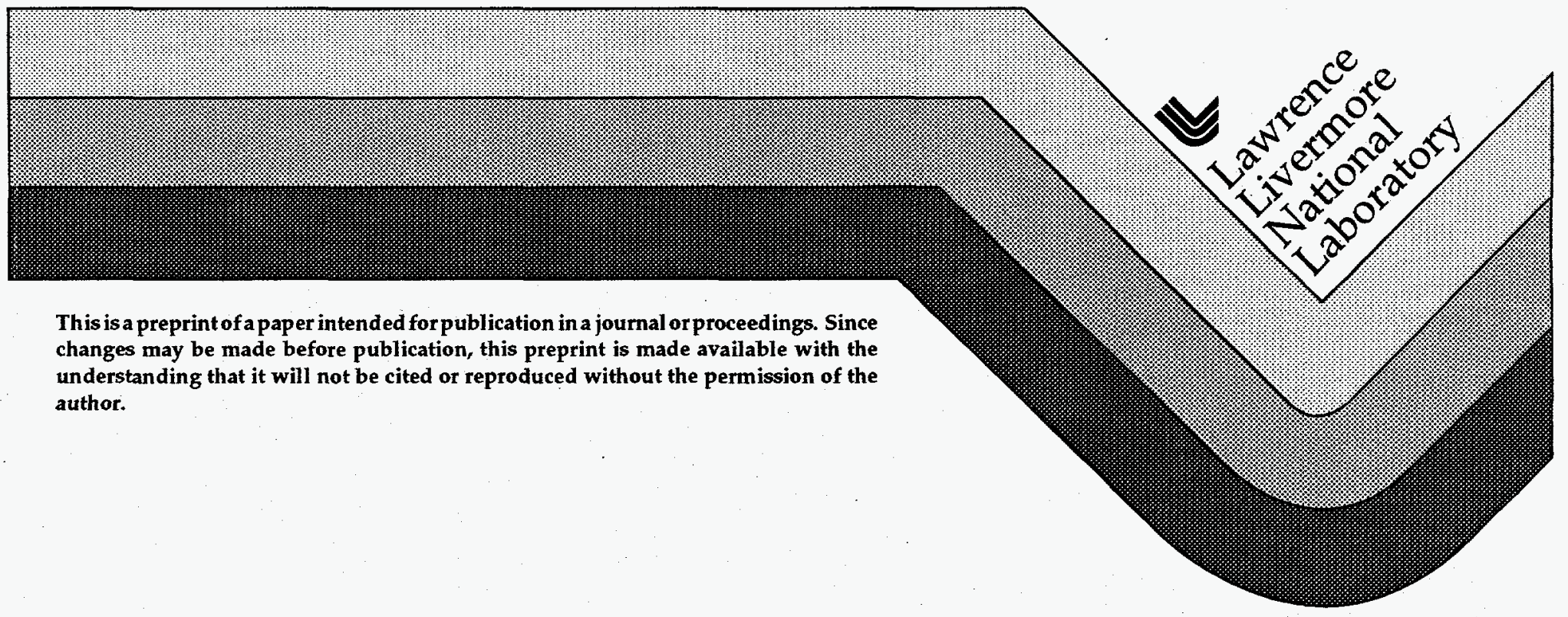




\section{DISCLAIMER}

This document was prepared as an account of work sponsored by an agency of the United States Government. Neither the United States Government nor the University of California nor any of their employees, makes any warranty, express or implied, or assumes any legal liability or responsibility for the accuracy, conapleteness, or usefulness of any information, apparatus, product, or process disdosed, or represents that its use would not infringe privately owned rights. Reference herein to inny specific commercial products, process, or service by trade name, trademark, manufacturer, or otherwise, does not necessarily constitute or imply its endorsement, recommendation, or favoring by the United States Government or the University of California. The views and opinions of authors expressed herein do not necessarily state or reflect those of the United States Government or the University of Califomia, and shall not be used for advertising or product endorsement parposes. 


\section{DISCLAIMER}

Portions of this document may be illegible in electronic image products. Images are produced from the best available original document. 
Autoignition Chemistry of the Hexane Isomers:

An Experimental and Kinetic Modeling Study

\author{
Henry J. Curran, Paolo Gaffuri, William J. Pitz, Charles K. Westbrook \\ Lawrence Livermore National Laboratory, Livermore, CA 94550 \\ and \\ William R. Leppard \\ General Motors Research Laboratories, Warren, MI 47090
}

\begin{abstract}
Autoignition of the five distinct isomers of hexane is studied experimentally under motored engine conditions and computationally using a detailed chemical kinetic reaction mechanism. Computed and experimental results are compared and used to help understand the chemical factors leading to engine knock in spark-ignited engines and the molecular structure factors contributing to octane rating for hydrocarbon fuels. The kinetic model reproduces observed variations in critical compression ratio with fuel structure, and it also provides intermediate and final product species concentrations in very close agreement with observed results. In addition, the computed results provide insights into the kinetic origins of fuel octane sensitivity.
\end{abstract}

\title{
INTRODUCTION
}

Combustion efficiency in spark-ignition engines increases as compression ratio is increased, but these increases in compression ratio lead eventually to the onset of engine knock. Engine knock therefore provides a practical limit to combustion efficiency in spark-ignition engines. Fuel additives are routinely incorporated into automotive fuels to avoid knocking behavior, and fuel components are blended to provide fuels with desired knock resistance. However, most of these processes are guided more by experience and empirical rules than by fundamental understanding of the basic chemistry of fuel/air autoignition in engines. Fundamentally based methods of predicting the knock tendencies of arbitrary fuel mixtures and fuel/additive mixtures could provide an extremely valuable tool in engine and fuel design efforts.

Hydrocarbon fuel molecular size and structure play very significant roles in determining knock tendency and octane rating in spark-ignition engines [1]. Recent experimental [2-9] and kinetic modeling [10,11] studies have provided a great deal of information that is leading to a detailed understanding of the elementary chemical factors that influence engine knock. In particular, these studies have indicated that distinctions between different carbon-hydrogen bonds and variations in ring strain energy, especially affecting the rates of alkylperoxy radical isomerization reactions, were most important in explaining these factors. Our previous kinetic modeling studies $[10,11]$ have placed these theories on a sound quantitative basis. The present work
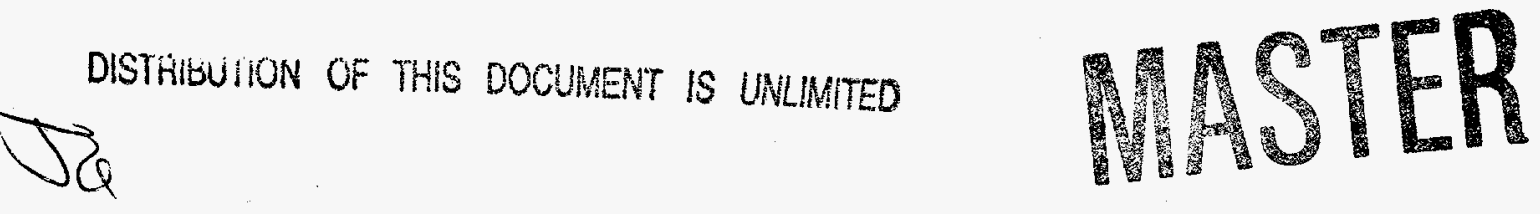
represents a further attempt to provide some fundamental understanding of knock chemistry.

The isomeric forms of hexane represent a very interesting family of fuels for the study of knock chemistry. The five isomers include the linear $n$-hexane (with a research octane number RON of 25), the singly-branched isomers 2-methyl pentane ( $R O N=73$ ) and 3-methyl pentane ( $\mathrm{RON}=75$ ), and the doubly-branched isomers 2,2-dimethyl butane (RON=92) and 2,3-dimethyl butane (RON=104). These fuels follow the general pattern familiar for alkane fuels, with the octane number increasing with the degree of branching in the fuel molecule. However, most of the other combustion properties of these fuels are extremely similar, including adiabatic flame temperature and laminar burning velocity. The clear conclusion is that the variability in octane number and knock tendency is due entirely to the molecular structure of these isomers.

In the present work, all five hexane isomers have been used in an experimental engine study, employing techniques that we have been using for many years to study fuel chemistry effects on engine knock and to provide information on autoignition chemistry. In addition, kinetic modeling analysis of these fuel ignition processes under engine conditions has been applied to interpret the experimental results and refine our ability to understand the basic fuel chemistry of autoignition of these fuels.

Our previous collaborations on experimental and kinetic modeling of autoignition chemistry [10] have provided a rather general picture of aliphatic hydrocarbon kinetics under engine conditions. The major features of this model involve the addition of molecular oxygen to alkyl radicals, followed by alkylperoxy radical isomerization [12] reactions, the rates of which vary with fuel structure and fuel size. This kinetic model was used to describe knocking tendencies of many paraffinic hydrocarbon fuels, with considerable success. In addition, the same model was used to show how different pro-knock and anti-knock additives such as tetra-ethyl lead, methyl-tert-butyl ether (MTBE), and other species altered fuel autoignition chemistry and changed the knock tendencies of hydrocarbon fuels. However, a limitation of this earlier model development was that it was tested only against octane number data for different hydrocarbon fuels, which are integrated quantities and cannot provide detailed chemical tests of the reaction mechanisms involved. In the present study, species-specific concentration measurements are used to test the model capabilities and motivate improvements in the model. As a result of these comparisons, a number of mechanism modifications were made that have improved its abilities to interpret and predict knock behavior. At the same time, other concurrent studies of alkane fuel oxidation in other experimental environments have also contributed to the refinement of our kinetic reaction mechanisms, which have improved the predictive capabilities of the overall model. 


\section{EXPERIMENTAL STUDIES}

Each hexane isomer was used as a fuel in a Waukesha Cooperative Fuels Research (CFR) engine operating under motored conditions. For each fuel, chemical species contrations for a wide range of species were measured in the cool exhaust stream under steady operation. The engine compression ratio was gradually increased until autoignition was observed. The CFR engine was modified to operate at higher than standard compression ratios. This critical compression ratio was found to vary from one fuel to another and depended strongly on fuel molecular structure.

For these motored engine studies, the extent of autoignition reaction chemistry was controlled by varying the compression ratio while holding the intake manifold temperature and pressure constant. Intake manifold temperatures and pressures were selected such that the extent of autoignition chemistry could be varied from a state of essentially no reactivity up to the point of autoignition while operating over a reasonable range of compression ratios. Experiments were carried out at an engine speed of $600 \mathrm{rpm}$, and intake temperature of $403 \mathrm{~K}$, and an intake manifold absolute pressure of $80 \mathrm{kPa}$.

All measurements were made with stoichiometric air-to-fuel ratios. Sample composition was continuously monitored during testing with a modified Beckman Model 109A Flame Ionization Detector (FID) sampling from the intake system just upstream from the intake valve. These intake system measurements were periodically confirmed by firing the engine and determining the equivalence ratio using standard exhaust-gas analysis.

A typical motored engine run involved stabilizing the intake temperature and pressure while motoring the engine on air at the desired speed and a very low compression ratio. After stabilization, the ignition was turned on and the fuel admitted. The fuel rate was adjusted to achieve an equivalence ratio of 1.0 as measured simultaneously by the intake charge FID and exhaust gas analyzers. The engine was fired for approximately ten minutes to assure stable fuel delivery and to burn any accumulated lubricating oil from the combustion chamber. At that point, the ignition was turned off and the compression ratio adjusted to the desired experimental setting. The continuous exhaust carbon monoxide analyzer is a good indicator of the extent of autoignition chemistry occurring for all fuels examined to date. After stable operating conditions were achieved, the carbon monoxide and oxygen exhaust concentrations were recorded, and exhaust gas samples acquired.

\section{Analytical Equipment}

Carbon monoxide was measured continuously using a Horiba Model AIA-23 Infrared Analyzer. Likewise, oxygen concentration was continuously measured using a Horiba Model MPA-21 Oxygen Analyzer. These on-line instruments were calibrated prior to each measurement with certified gaseous calibration standards. Exhaust sampling and analyses of other stable intermediate species were performed as described in previous publications [13-15]. Gas chromatography (GC) was the primary analytical 
technique for quantifying the stable intermediate species resulting from autoignition chemistry. Formaldehyde was quantified using the DNPH derivatization technique of Lipari and Swarin [16]

Exhaust gas samples for GC analysis were obtained either with heated, gas-tight syringes or with the gas sampling system described in [13]. These gaseous samples were analyzed using the two-dimensional gas chromatographic technique described in $[13,17]$. Unknown intermediate species were identified by a combination of gas chromatographic-mass spectrometry (GC-MS) and gas chromatography-Fourier transform infrared spectroscopy (GC-FTIR). The samples for the GC-MS and GC-FTIR analyses were liquid and were obtained by pulling a fraction of the exhaust through a condensation trap immersed in a dry ice-isopropanol bath. Liquid samples were used in preference to gaseous ones as the concentrations of the unknowns were higher providing better responses to both analytical techniques.

\section{Experimental Results}

The general experimental results are best summarized as shown in Fig. 1, showing the measured exhaust concentrations of carbon. monoxide for each hexane isomer as a function of compression ratio. Carbon monoxide concentrations in the exhaust represent a realistic measure of overall extent of reaction and heat release, so increasing levels of $\mathrm{CO}$ in Fig. 1 indicate a greater degree of overall reaction. For each fuel studied, the experimental results show that below a certain compression ratio, there is virtually no reaction. As the compression ratio increases, the extent of reaction in the motored engine increases until, at some critical value of the compression ratio, autoignition is observed, even without spark ignition in the combustion chamber.

The experimentally measured variation in critical compression ratio is directly correlated with research octane number (RON). The smallest critical compression ratio is observed for n-hexane, at a value for compression ratio of 6.36. Critical compression ratios for 2-methyl pentane and 3-methyl pentane are quite similar at about 8.2, and these two fuels have almost identical RON values of 73 and 75 . The next fuel is neohexane or 2,2-dimethyl butane, with an experimentally measured critical compression ratio of 11.5 and RON of 92 , significantly slower to react than the previous isomers of hexane. Finally, the least reactive of the hexane isomers is clearly 2,3-dimethyl butane, with a RON of 104 and a measured critical compression ratio of 18.6. For all five isomers, the progression in octane number is mirrored by the trend in critical compression ratio. This represents the first, and least demanding, requirement for the kinetic model to reproduce in order to validate the overall kinetic model.

A wide range of chemical species concentrations were measured in the exhaust gases at each value of engine compression ratio. Of particular interest are the concentration values at the highest experimental value of compression ratio that did not result in autoignition. Examples of the measured GC results are shown for three of the isomers of hexane, n-hexane, 3-methyl pentane, and 2,2-dimethyl butane, in Figs. 2-7, showing the separate results for hydrocarbons and oxygenated species. These results for each of the isomeric hexanes are also summarized in Tables V - IX. In each case, the 
major products are carbon monoxide, formaldehyde, ethene and a small number of other species which are common to all of these fuels. In addition, each fuel produces a wide variety of larger olefins and oxygenated hydrocarbon species, although the specific concentrations of each of these species varies, depending on the fuel being studied. In particular, these oxygenated species include alcohols, aldehydes, and a variety of epoxide species with different ring sizes and structures. We will return to these species-specific concentration results below, since they provide a great deal of insight into the details of oxidation chemistry and the variations with the structure of the hexane isomers.

\section{COMPUTATIONAL MODEL}

All of the modeling computations in this study were carried out using the HCT model [18]. This model has been used in a large number of investigations over the past years, and in particular was used in our past studies of engine knock and autoignition $[10,11,19,20]$. The HCT code permits the use of a variety of boundary and intial conditions for reactive systems, depending on the needs of the particular system being examined. In the present case, the relevant conditions are those which describe the bulk gases in the combustion chamber under motored conditions.

During motored operation in this engine, a number of processes occur which influence the time variation of the temperature and pressure of the bulk reactive gases in the combustion chamber. Piston motion first compresses and heats the bulk gases and then expands and cools them. During this time, some chemical activity occurs, releasing some heat and changing the overall composition of the gases. At the end of each engine cycle, fresh unreacted fuel and air are added to residual gases left over from the previous cycle. In contrast with residual gases from fired engine cycles which consist largely of water vapor, $\mathrm{CO}_{2}, \mathrm{CO}$ and molecular nitrogen, residual gases under these motored conditions consist of a complex mixure of partially reacted fuel species and $\mathrm{N}_{2}$. These partially reacted species can have a significant influence on the reactivity of the overall gas mixture in the combustion chamber, as discussed in detail by Green et al. [21], an effect which varies with engine compression ratio and which must be included in the kinetic modeling analysis. In addition, heat losses to the engine chamber walls, blowby, fuel trapping in crevice volumes, and other processes occur.

The computational model treats the combustion chamber as a homogeneous reactor with a variable volume. The volume is changed with time using a slider-crank formula as described by Heywood [22] and used in previous modeling studies [10,21]. The formula uses the engine speed and compression ratio, together with the piston stroke. The present model ignores spatial variations in the engine chamber, treating heat loss as a distributed heat transfer rate, proportional to the temperature difference between the average gas temperature and a time-averaged wall temperature. The coefficient of proportionality is an effective heat transfer coefficient that is determined in the following manner. Two sets of experiments were carried out in the engine with 
(1) compression ratios sufficiently low that no $\mathrm{CO}$ was produced, and (2) with no fuel present, ensuring that no heat release due to chemical reaction was possible. The heat transfer coefficient was then varied to reproduce as closely as possible the observed average pressure and temperature histories in the engine chamber. The result of this process is illustrated in Fig. 8 for a compression ratio of 6.63. The computed pressure is shown as the solid curve and the measured values are indicated by the dashed curve.

At each compression ratio, experimental data provided the initial gas temperature, the recyle gas fraction, and the initial pressure used for the simulation. As the reaction time increases, the slider-crank formula and heat transfer rate account for all of the relevant processes except chemical reaction, which is computed explicitly in the kinetics portion of the model as described next.

\section{REACTION MECHANISMS}

The detailed chemical kinetic reaction mechanism used in these calculations was based on that used in our previous knock modeling stuclies [10,11]. The base mechanism has been assembled hierarchically, starting with a core describing $\mathrm{H}_{2} / \mathrm{O}_{2}$ and $\mathrm{CO}$ oxidation. This is then extended sequentially to treat methane $\left(\mathrm{CH}_{4}\right)$, ethane $\left(\mathrm{C}_{2} \mathrm{H}_{6}\right)$, propane $\left(\mathrm{C}_{3} \mathrm{H}_{8}\right)$, and isomers of butane $\left(\mathrm{C}_{4} \mathrm{H}_{10}\right)$ and pentane $\left(\mathrm{C}_{5} \mathrm{H}_{12}\right)$, together with the many reactive intermediate species produced during the combusion of these alkane fuels. The detailed submechanism for each isomer of hexane was then added to this common base mechanism. This approach for developing hierarchical kinetic reaction mechanisms was first discussed by Westbrook and Dryer [23,24]. The result for each isomer is a reaction mechanism with approximately 375 different chemical species and 1750 elementary reactions, with about 90 of these species and 300 reactions specific to the hexane species and its possible products, and 285 species and 1450 reactions describing the $C_{1}-C_{5}$ core mechanism.

Many of the details of these reaction mechanisms are exactly the same as described in our previous work [10], but there are a number of significant improvements that have been made. One major change has been a complete update of the thermochemical variables for many of the chemical species in the model, using the bond additivity rules of Benson [25] as implemented by Ritter and Bozzelli with updated $\mathrm{H} / \mathrm{C} / \mathrm{O}$ groups and bond dissociation groups [26,27]. For many of the elementary reactions in the model, the reaction rate is given in one direction and equilibrium constants are then used to determine the reverse reaction rate. Improved thermochemistry thus has a significant impact on the kinetic rate parameters in the reaction mechanism. In order to make the other mechanism modifications clear, the overall reaction path should be described, as follows. 


\section{Fuel consumption}

Under the conditions of a motored engine and in spark-ignited engines under conditions leading to engine knock, nearly all fuel consumption occurs as a result of $H$ atom abstraction reactions. As in the previous study, these abstraction reactions occur with $\mathrm{H}, \mathrm{O}, \mathrm{OH}, \mathrm{HO}_{2}, \mathrm{CH}_{3}$, and other less important radical species. Distinctions are made between the abstraction of $\mathrm{H}$ atoms from primary, secondary, and tertiary sites in the fuel molecule. These distinctions play an important role in determining octane ratings and knock tendency, as described previously [10].

\section{Alkyl radical reactions}

Although $\beta$-scission of alkyl radicals (denoted generally by $R$ ) is included in the mechanism, under the present conditions most of these radicals react via addition of $\mathrm{O}_{2}$. The addition rate used here is the same as that in our previous model, but the reverse rate is now computed from equilibrium constants, resulting in a more accurate description of the partial equilibrium between $\mathrm{R}$ and the peroxy radical $\mathrm{RO}_{2}$.

\section{Alkyl peroxy isomerizations}

Internal $\mathrm{H}$ atom transfer within the $\mathrm{RO}_{2}$ species to produce a species denoted as $\mathrm{QOOH}$ is a very important step in the low temperature oxidation of these classes of fuels. We have greatly improved the treatment of these reactions in the mechanism, the rates of which vary depending on the type of $\mathrm{C}-\mathrm{H}$ bond being broken and the size of the intermediate transition state ring involved in the reaction: The activation energies for these reactions have been revised from the previous model, and the A factors for these reaction rates have been revised to account for the entropy changes involved as the transition state ring increases in size. The resulting rates of these reactions are summarized in Table I. Another important mechanism upgrade concerns the use of improved equilibrium constants to calculate the reverse reaction rates of these isomerization reactions, rather than explicitly prescribing the reverse reactions as done previously.

\section{QOOH reactions.}

There are four reaction paths which these species can follow in addition to reverse isomerization back to $\mathrm{RO}_{2}$. These reactions include addition of another $\mathrm{O}_{2}$ species to produce $\mathrm{O}_{2} \mathrm{QOOH}$ species, $\mathrm{O}$ - O homolysis followed by the formation of cyclic ether products (rate expressions are given in Table I), and two reaction paths that are possible only for certain types of $\mathrm{QOOH}$ radicals. For $\mathrm{Q} O \mathrm{OH}$ species formed through 5-membered intermediate transition state rings, the free radical site is immediately adjacent to the $\mathrm{OOH}$ site (also denoted as the $\alpha$-site). For these structured radicals, the entire $\mathrm{OOH}$ portion can be removed by breaking the $\mathrm{C}-\mathrm{O}$ bond, leaving an olefin product and an $\mathrm{HO}_{2}$ radical. All of these reaction paths were included in the previous mechanisms, but improved thermochemical data affect all of the reverse reaction rates for them. 
Table I Selected rate expressions involving peroxy radicals

Rate expression per $\mathrm{H}$ atom

Ring size

Primary

Secondary

Tertiary

Alkylperoxy radical isomerization

5
6
7
8

$$
\begin{aligned}
& 2.97 \times 10^{12} \exp (-29700 / R T) \\
& 2.47 \times 10^{11} \exp (-23900 / R T) \\
& 2.06 \times 10^{10} \exp (-21100 / R T) \\
& 1.72 \times 10^{09} \exp (-23900 / R T)
\end{aligned}
$$$$
2.97 \times 10^{12} \exp (-27900 / \mathrm{RT})
$$$$
2.47 \times 10^{11} \exp (-22150 / \mathrm{RT})
$$$$
2.59 \times 10^{12} \exp (-25400 / \mathrm{RT})
$$$$
2.06 \times 10^{10} \exp (-19350 / \mathrm{RT})
$$$$
1.72 \times 10^{09} \exp (-22150 / \mathrm{RT})
$$

Peroxyalkylhydroperoxy radical isomerization

$\begin{array}{lll}5 & 1.49 \times 10^{12} \exp (-26700 / \mathrm{RT}) & 1.49 \times 10^{12} \exp (-24900 / \mathrm{RT}) \\ 6 & 1.24 \times 10^{11} \exp (-20900 / \mathrm{RT}) & 1.24 \times 10^{11} \exp (-19150 / \mathrm{RT}) \\ 7 & 1.04 \times 10^{10} \exp (-18100 / \mathrm{RT}) & 1.04 \times 10^{10} \exp (-16350 / \mathrm{RT}) \\ 8 & 8.64 \times 10^{08} \exp (-20900 / \mathrm{RT}) & 8.64 \times 10^{08} \exp (-19150 / \mathrm{RT})\end{array}$

\section{Cyclic ether formation}

Heterocycle

oxirane

oxetane

furan

pyran
Rate Expression

$$
\begin{aligned}
& 3.00 \times 10^{11} \exp (-22000 / \mathrm{RT}) \\
& 2.50 \times 10^{10} \exp (-15250 / \mathrm{RT}) \\
& 2.08 \times 10^{09} \exp (-6500 / \mathrm{RT}) \\
& 1.74 \times 10^{08} \exp (-1800 / \mathrm{RT})
\end{aligned}
$$


However, a final group of reactions of $\mathrm{QOOH}$ have been added for the present simulations that had not been considered in the previous mechanism. When the $\mathrm{QOOH}$ is produced through a 6-membered transition state, the product $Q O O H$ can decompose via $\beta$-decomposition, as described by Pollard [12] and discussed by Leppard [13]. Rather than the cyclic ether products resulting from the cyclization reactions of the $\mathrm{QOOH}$ species already included in the mechanism, this reaction path produces smaller olefins and partially oxidized species including ketones and aldehydes which have different reactivities than the cyclic ethers. Both reaction sequences produce $\mathrm{OH}$ radicals and are effectively chain propagation reaction paths.

\section{Formation and decomposition of ketohydroperoxide species}

In our previous model, the $\mathrm{O}_{2} \mathrm{QOOH}$ species were assumed to react via internal $\mathrm{H}$ atom transfer, following the above model for $\mathrm{RO}_{2}$ isomerization, followed immediately by decomposition of the product to a large number of radical, partially oxidized, and olefin species, including two $\mathrm{OH}$ radicals. As a result, the reaction of $\mathrm{O} 2 \mathrm{QOOH}$ had a significant effect on the overall reaction scheme, providing a great deal of chain branching. For the present mechanism, we have used experience derived from the lumped reaction mechanism work of Ranzi et al. $[28,29]$ in which the reaction sequence for $\mathrm{O}_{2} \mathrm{QOOH}$ was simulated in a somewhat different manner. Specifically, following the internal isomerization $\mathrm{H}$ atom transfer, it is assumed that an $\mathrm{O}-\mathrm{O}$ bond is broken, producing $\mathrm{OH}$ radicals and a ketohydroperoxide species which is relatively stable. This ketohydroperoxide intermediate remains until the temperature increases enough for it to decompose or until it exists in sufficient quantities that its overall rate of decomposition is significant. The products of the ketohydroperoxide decomposition are assumed to be $\mathrm{OH}$ radicals, a carbonyl radical, and other smaller stable species. For convenience, these product species are assumed to be species already present in the larger reaction mechanism, even when it is likely that other species are more likely decomposition products. The consequences of this assumption will become clear later in the discussion of the computed results. In addition, the activation energy for the decomposition is assumed to be $43 \mathrm{kcal} / \mathrm{mol}$ for all of the different ketohydroperoxides. While it is clear that each such species will have slightly different thermochemistry and activation energies for decomposition, at present this assumption that the activation energies are all equal is appropriate, given the other approximations inherent in the model. This description has been incorporated into the present detailed kinetic reaction mechanism. The rate expressions for the $\mathrm{O} 2 \mathrm{QOOH}$ isomerization reactions are summarized in Table I.

This mechanism modification has two important results. First, since the production of ketohydroperoxide species is accompanied by production of only one $\mathrm{OH}$ radical, it retards chain branching until the ketohydroperoxide species decomposes. This is in contrast with our earlier model in which $\mathrm{O}_{2} \mathrm{QOOH}$ isomerization led immediately to several radical species products. Furthermore, production of the relatively stable species produces a form of induction time in many of the computed 
results, a phenomenon not available in the previous mechanism and which has been found to be important in simulations of some types of kinetic problems [wss,2].

All of these reaction mechanism modifications were developed and tested in extensive modeling studies [30] of the oxidation of primary reference fuels, $n$-heptane and iso-octane (2,2,4-trimethyl pentane), including simulations of experiments in shock tubes, turbulent flow reactors, stirred reactors, and rapid compression machines. All of the experiments exhibited phenomena including self ignition, cool flames, and a negative temperature coefficient. Reaction rates for hexane species, intermediates and radical species were adopted directly without further modification from analogous reactions in $\mathrm{n}$-heptane and iso-octane, using the same rules including those illustrated in Table I.

\section{COMPUTED RESULTS}

Using initial conditions derived from the experirnents as described above, engine simulations were carried out for stoichiometric fuel/air mixtures of each of the isomeric forms of hexane. Each cycle simulation began at the time of intake valve closing at 151.8 degrees before top dead center (TDC), with an engine speed of $600 \mathrm{rpm}$. In each case, for the first engine cycle the fuel/air mixture consisted entirely of unreacted hexane and air; on subsequent cycles the initial mixture consisted of unreacted fuel/air and an appropriate fraction of the residual products of the previous cycle. Enough cycles were computed in this manner until the products of a given cycle were essentially identical to those of the previous cycle, with occasional exceptions as noted below. For example, the concentrations of certain selected species concentrations at the end of each of 6 motored cycles at a compression ratio of 7.75 using neo-hexane (2,2dimethyl butane) are shown in Table II.

$\begin{array}{llllll}\text { Cycle } & \text { neohexane } & \mathrm{CO}_{2} & \mathrm{CH}_{2} \mathrm{O} & \mathrm{CO} & \text { acetone } \\ 1 & 1.28 \mathrm{e}-2 & 1.56 \mathrm{e}-4 & 5.73 \mathrm{e}-3 & 7.45 \mathrm{e}-3 & 2.45 \mathrm{e}-4 \\ 2 & 1.33 \mathrm{e}-2 & 2.53 \mathrm{e}-4 & 5.35 \mathrm{e}-3 & 8.31 \mathrm{e}-3 & 2.44 \mathrm{e}-4 \\ 3 & 1.32 \mathrm{e}-2 & 2.44 \mathrm{e}-4 & 5.40 \mathrm{e}-3 & 8.32 \mathrm{e}-3 & 2.40 \mathrm{e}-4 \\ 4 & 1.32 \mathrm{e}-2 & 2.45 \mathrm{e}-4 & 5.39 \mathrm{e}-3 & 8.28 \mathrm{e}-3 & 2.40 \mathrm{e}-4 \\ 5 & 1.32 \mathrm{e}-2 & 2.44 \mathrm{e}-4 & 5.38 \mathrm{e}-3 & 8.27 \mathrm{e}-3 & 2.40 \mathrm{e}-4 \\ 6 & 1.32 \mathrm{e}-2 & 2.44 \mathrm{e}-4 & 5.38 \mathrm{e}-3 & 8.27 \mathrm{e}-3 & 2.40 \mathrm{e}-4\end{array}$

Table II. Selected simulated engine-out species concentrations at $\mathrm{CR}=7.75$ for a sequence of 6 consecutive cycles with neohexane fuel.

When the product species concentrations eventually converged as illustrated here, the sequence of cycles was terminated and a new sequence was begun at an increased compression ratio. Eventually, for each isomer of hexane, a compression ratio was 
reached at which autoignition was observed during the engine cycle. On most occasions, this autoignition was predicted to occur not on the first cycle but after several cycles during which concentrations of intermediate species were seen to increase steadily from one cycle to the next. An example of this behavior can be seen in Table III in the case of $n$-hexane at a compression ratio of 5.75 .

$\begin{array}{llllll}\text { Cycle } & \text { n-hexane } & \mathrm{CO} & \mathrm{CO}_{2} & \mathrm{CH}_{2} \mathrm{O} & \mathrm{CH}_{3} \mathrm{CHO} \\ 1 & 2.16 \mathrm{e}-2 & 3.54 \mathrm{e}-11 & 1.00 \mathrm{e}-13 & 1.36 \mathrm{e}-11 & 8.01 \mathrm{e}-11 \\ 2 & 2.16 \mathrm{e}-2 & 6.25 \mathrm{e}-10 & 2.80 \mathrm{e}-12 & 2.37 \mathrm{e}-10 & 1.39 \mathrm{e}-9 \\ 3 & 2.16 \mathrm{e}-2 & 8.67 \mathrm{e}-9 & 5.09 \mathrm{e}-11 & 3.34 \mathrm{e}-9 & 1.93 \mathrm{e}-8 \\ 4 & 2.16 \mathrm{e}-2 & 1.18 \mathrm{e}-7 & 1.93 \mathrm{e}-9 & 5.26 \mathrm{e}-8 & 2.66 \mathrm{e}-7 \\ 5 & 2.15 \mathrm{e}-2 & 1.71 \mathrm{e}-6 & 6.52 \mathrm{e}-8 & 1.23 \mathrm{e}-6 & 3.94 \mathrm{e}-6 \\ 6 & 1.78 \mathrm{e}-2 & 1.86 \mathrm{e}-4 & 8.32 \mathrm{e}-6 & 1.72 \mathrm{e}-4 & 1.86 \mathrm{e}-4 \\ 7 & \text { autoignition } & & & & \end{array}$

Table III. Selected simulated engine-out species concentrations at $\mathrm{CR}=5.75$ for a sequence of 7 consecutive cycles with $n$-hexane fuel.

At higher values of the compression ratio, autoignition continued to be observed in the computed results, so just as in the experiments, a critical value for the compression ratio was determined. The results are ambiguous only in the case of $n$-hexane, which as shown in Table III was predicted to autoignite for all values of compression ratio for which experimental data on temperature and pressure at the time of intake valve closing were available. However, as seen in Table III, and by comparing this behavior with computed results for the other hexane isomers at compression ratios slightly above their critical value, it is very likely that the critical compression ratio for $n$-hexane is only slightly less than this value of 5.75 .

The numerically determined values for these critical compression ratios are compared with the experimental results in Table IV.

$\begin{array}{lcc}\text { Hexane isomer } & \begin{array}{c}\text { Experimental } \\ \text { Crit. CR }\end{array} & \begin{array}{c}\text { Computed } \\ \text { Crit. CR }\end{array} \\ \text { n-hexane } & 6.4 & (5.7) \\ \text { 2-methyl pentane } & 8.1 & 8.75 \\ \text { 3-methyl pentane } & 8.4 & 8.75 \\ \text { 2,2-dimethyl butane } & 11.5 & 10.5 \\ \text { 2,3-dimethyl butane } & 19.0 & 14.5\end{array}$

Table IV. Experimental and numerically predicted values for critical compression ratios of hexane isomers. 
The general trends are reproduced extremely well by the numerical model. The ranking of the different hexane isomers is correctly predicted, and the specific numerical values for each fuel are also quite close to the observed values. In addition, the observation that 2-methyl pentane and 3-methyl pentane are very similar in their autoignition behavior is also very well reproduced by the numerical model. Perhaps the most notable shortcoming of the model is that it does not reflect the unusually strong autoignition resistance of the least reactive isomer, 2,3-dimethyl butane.

\section{Fuel Octane Sensitivity}

The computational results show several interesting features that were not observed in the experiments. In the cases of 2-methyl pentane, 3-methyl pentane, and 2,2-dimethyl butane, at compression ratios substantially lower than the critical value, autoignition was predicted by the model calculations. However, as the compression ratio was further increased, the autoignition behavior disappeared and did not reappear until reaching the critical value indicated in Table IV. For 2-methyl pentane, autoignition was predicted for compression ratios of 7.25, 7.5 and 7.75, while at compression ratios of 8.0 through 8.75 no autoignition was predicted. Similarly, in the case of 3-methyl pentane, autoignition was predicted at a compression ratio of 7.75, while no ignition was predicted at lower compression ratios or at higher values until the critical value of 8.75 was exceeded. For 2,2-dimethyl butane, similar autoignition was computed at a compression ratio of 7.5, with lower and higher $C R$ values indicating no autoignition until the critical value of 10.5 was exceeded.

Closer examination of the computed behavior in these models for these intermediate igniting cases shows that these fuel/air mixtures are passing through a region of negative temperature coefficient. For all three of these fuels, the reactive mixtures at compression ratios close to the 7.5 - 7.75 range reach temperatures where the overall rate of reaction reaches a temporary maximum. As a result, these mixtures are predicted to ignite. Then, as the compression ratio increases above 7.75 , the temperatures at TDC pass into this negative temperature coefficient region, and the overall rate of reaction actually decreases for a period, resulting in non-igniting behavior. Finally, at compression ratios above 8.75 for 2-methyl pentane and 3-methyl pentane, the overall rate of reaction reaches the same level as that computed at a compression ratio of 7.75 and ignition is again predicted. Qualitatively, the same behavior is predicted for 2,2-dimethyl butane, but this fuel is significantly less reactive at these conditions than the 2-methyl and 3-methyl pentanes, and a significantly greater subsequent compression, to a value of 10.5 , is required to achieve the same degree of reactivity.

The experimental results do not indicate this intermediate more reactive region at compression ratios considerably lower than the critical value. However, the experiments in the case of 2-methyl pentane showed only sporadic ignition at a compression ratio of 8.0 , indicating that not every cycle ignited. Originally, it was 
assumed that conventional cycle-to-cycle variations were responsible for this behavior, but the same phenomena indicated in the computations could also have contributed.

Additional evidence of NTC behavior for these fuels is provided by earlier motored engine experiments carried out by Leppard [13-15] under conditions including different engine speeds, a range of intake manifold temperatures and pressures, and a variety of paraffin, olefin and aromatic fuels. Leppard examined the problem of fuel octane sensitivity, comparing chemical reactivity of selected fuels under both Research and Motor conditions. That work indicated that the higher temperatures, lower pressures, and shorter residence times encountered under the Motor octane test procedures would accentuate NTC behavior of alkane fuels, leading to what he termed "super-rated Motor octane quality" for paraffin fuels. As a result of NTC behavior of paraffinic fuels, under Motor octane test procedures, ignition is delayed until higher compression ratios. The corresponding ignition of aromatic and olefinic fuels is not retarded by NTC behavior to any significant degree, leading to poorer octane quality under Motor conditions. As pointed out by Leppard, it is actually more appropriate to regard aromatic and olefin fuels as representing "normal" behavior, with paraffins representing unusual trends due to the influence of the NTC for these fuels.

Another feature of the computed results for the same intermediate fuels, 2methyl pentane, 3-methyl pentane, and 2,2-dimethyl butane, was observed at compression ratios lower than this intermediate igniting region. At these conditions, the results for sequential simulated cycles demonstrated a form of oscillatory behavior in which computed engine-out concentrations of species such as $\mathrm{CO}, \mathrm{CO}_{2}$, and many others alternated from one cycle to the next, with high values on one cycle and low values on the next cycle. This oscillating behavior appears similar to that seen for hydrocarbons in stirred and static reactors $[4,9]$. When the compression ratio was then increased, the mixtures would autoignite for a range of compression ratios, after which a period of no ignition was computed, followed ultimately by the onset of autoignitions that persisted as compression ratio was increased further. This behavior provides another indication that NTC conditions are influencing the computed results in a profound manner.

For the most part, the NTC features predicted by the model calculations were not seen in the experiments. There are many reasons why this could be expected. The species measurements were averaged over hundreds of cycles so that any oscillatory behavior would be smoothed out. Perhaps most important, the model assumption of homogeneous reaction in the engine chamber, combined with a distributed heat loss rate, is only approximately valid. Spatial temperature variations exist in the experiments due to heat transfer to the engine chamber walls. Under most conditions, these variations do not have a great influence on the overall system behavior, but under conditions close to the NTC region, if there are areas in the chamber with different temperatures, these areas will demonstrate differing responses to temperature increases. Subtle phenomena depending on small variations in temperature may not be noticed in the experimental system of the engine. 


\section{Chemical Species Concentrations}

There is an enormous amount of information in the results of the model calculations. Most important are the predicted values of species concentrations during each cycle and at the end of the converged multi-cycle simulations. As noted earlier, it was convenient to represent the experimental results in terms of the engine-out $\mathrm{CO}$ concentrations. Comparable results from the model simulations are shown in Fig. 9, and comparison with the experimental results from Fig. 1 shows that the overall results are in good agreement. This agreement is emphasized in Fig. 10, showing the experimental and computed results together on the same scale for compression ratio.

From Figs. 9 and 10, the inflections in the curves for 2-methyl pentane and 3methyl pentane suggest NTC behavior in these histories, and this behavior is even more obvious in the computed CO profile for 2,2-dimethyl butane. The NTC region for 2,2dimethyl butane can also be seen from the experimental $\mathrm{CO}$ results in Fig. 1 and Fig. 10, although the measured values remain relatively constant through this region rather than pass through a minimum as computed by the model. The rather abrupt onset of ignition in the case of 2,3-dimethyl butane is also captured by the model, although the critical compression ratio is predicted to be somewhat lower than in the experiments.

In the experiments, a combination of analytical techniques were used to determine the concentrations of different chemical species in the gases leaving the engine chamber. These can be compared with the computed results as a much more demanding test of the models. It is convenient to use the chemical species values evaluated at the highest compression ratio for which autoignition was not observed or predicted, since this is the situation for which the greatest degree of fuel consumption would be expected. The results for each of the isomeric hexanes are summarized in Tables V - IX. 
Species

Carbon monoxide

Carbon dioxide

Methane

Methanol

Formaldehyde

Ethene

Acetaldehyde

Propionaldehyde

Propene

Acrolein

Propene oxide

1-butene

Methyl vinyl ketone

Methyl ethyl ketone

1-pentene

1-hexene

2-hexene

2-methyl-4-ethyloxetane

2,5-dimethyltetrahydrofuran

2-propyloxetane

2-ethyltetrahydrofuran
Model

Concentration

(ppm)

1378

258

28

92

418

180

306

159

102

50

17

58

19

22

13

65

76

51

61

8

32
Experimental

Concentration

(ppm)

168

8

14

172

134

186

51

55

1

3

5

$-$

$-$

1

19

23

5

139

2

88

Table V. Experimental and computed species concentrations for oxidation of $n$-hexane. Experimental results are made at $C R=7.15$, model results evaluated at $C R=5.75$. 


$\begin{array}{lcc}\text { Species } & \begin{array}{c}\text { Model } \\ \text { Concentration } \\ \text { (ppm) }\end{array} & \begin{array}{c}\text { Experimental } \\ \text { Concentration } \\ \text { (ppm) }\end{array} \\ \text { Carbon monoxide } & 6390 & \\ \text { Carbon dioxide } & 1150 & 9760 \\ \text { Methane } & 166 & 275 \\ \text { Methanol } & 2644 & 6 \\ \text { Formaldehyde } & 2107 & 439 \\ \text { Ethene } & 579 & 4800 \\ \text { Acetaldehyde } & 1457 & 2300 \\ \text { Propionaldehyde } & 479 & 686 \\ \text { Acetone } & 1382 & 744 \\ \text { Acrolein } & 159 & 2400 \\ \text { Isobutene } & 534 & 169 \\ \text { Methyl vinyl ketone } & 78 & 453 \\ \text { Methyl ethyl ketone } & 142 & -- \\ \text { 2-pentene } & 180 & -- \\ \text { 4-methyl-1-pentene } & 90 & 239 \\ \text { 2-methyl pentane } & 12505 & 153 \\ \text { 2-methyl-1-pentene } & 356 & 8860 \\ \text { 2-methyl-2-pentene } & 215 & 827 \\ \text { 2,2,4-trimethyloxetane } & 243 & 872 \\ \text { 2,2-dimethyltetrahydrofuran } & 323 & 244 \\ \text { 2,4-dimethyltetrahydrofuran } & 248 & 498 \\ & & 414\end{array}$

Table VI. Experimental and computed species concentrations for oxidation of 2-methyl pentane. Experimental results are made at $C R=8.0$, model results evaluated at $\mathrm{CR}=8.75$. 
Species

Carbon monoxide

Carbon dioxide

Methane

Methanol

Formaldehyde

Ethene

Acetaldehyde

Propionaldehyde

Acetone

Propene

1-butene

2-butene

Methyl vinyl ketone

Methyl ethyl ketone

2-methyl-1-butene

2-pentene

3-methyl-1-pentene

2-ethyl-1-butene

3-methyl-2-pentene

3-methyl pentane

2,3,4-trimethyloxetane

2,3-dimethyltetrahydrofuran

2-methyl-2-ethyloxetane

2-methyl-3-ethyloxetane

2-ethyltetrahydrofuran
Model

Concentration

(ppm)

5800

1200

148

2850

2034

667

2229

175

203

84

208

483

307

722

290

119

265

361

443

13917

347

200

216

213

37
Experimental Concentration

(ppm)

10900

293

28

678

5360

3370

2500

62

40

1170

219

195
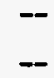

466

125

314

492

2090

9830

78

388

130

43

128

Table VII. Experimental and computed species concentrations for oxidation of 3-methyl pentane. Experimental results are made at $C R=8.0$, model results evaluated at $C R=8.75$. 
Species

Carbon monoxide

Carbon dioxide

Methane

Methanol

Formaldehyde

Ethene

Acetaldehyde

Acetone

Propene

Isobutene oxide

Isobuteraldehyde

Methacrolein

Methyl vinyl ketone

Methyl ethyl ketone

2-methyl-1-butene

Isoprene

3,3-dimethyl-1-butene

2-methyl-2-butene

2,2-dimethyl butane

3-methyl-3-butene-2-one

2,3,3-trimethyloxetane

3,3-dimethyltetrahydrofuran

3,3-methyl,ethyloxetane
Model

Concentration

(ppm)

4780

645

107

1220

1870

9709

1128

1289

65

159

33

205

63

151

209

72

906

423

12920

115

528

239

53
Experimental

Concentration

(ppm)

8160

196

22

408

4760

2230

821

361

1470

77
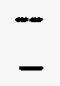

$-$

--

192

13

637

2130

12200

168

403

24

Table VIII. Experimental and computed species concentrations for oxidation of 2,2-dimethyl butane. Experimental results are made at $C R=11.25$, model results evaluated at $C R=10.5$. 


$$
\text { Species }
$$

Carbon monoxide

Carbon dioxide

Methane

Methanol

Formaldehyde

Ethene

Acetaldehyde

Acetone

Propene

3-methyl-1-butene

Isoprene

2-methyl-2-butene

2,3-dimethyl butane

2,3-dimethyl-2-butene

2,2,3-trimethyloxetane

3-methyl-3-butene-2-one
Model

(ppm)

435

45

16

173

761

10

439

659

390

16

52

428

19350

77

616

72
Experimental

Concentration

(ppm)

4120

122

5

24

2410

1600

112

1790

1890

157

9

1130

11100

2170

192

Table IX. Experimental and computed species concentrations for oxidation of 2,3-dimethyl butane. Experimental results are made at $C R=18.5$, model results evaluated at $\mathrm{CR}=14.0$. 
For the most part, the agreement between computed and experimental species concentrations is excellent, especially when it is considered that these are timeintegrated quantities that cover production and consumption of these species over a wide range of temperature and time. The total fractions of large olefins, cyclic ethers, oxygenated species including aldehydes and ketones, all are excellent agreement with observations, and the relative distributions of different isomeric forms of these intermediates are also well reproduced by the model.

There is considerable information even in the significant errors or omissions of the model. For example, for 3-methyl pentane, a major product is measured to be methyl-ethyl ketone, which is not included in the reaction mechanism. However, upon inspection of the details of the reaction mechanism, it is clear that the major reaction path that produces methyl-ethyl ketone is the following:

Abstraction of $\mathrm{H}$ atoms at the tertiary site in the fuel

$$
C-C-\stackrel{C}{C}-C-C
$$

followed by addition of molecular oxygen,

$$
C-C-\stackrel{C}{C}-C-C
$$

followed by internal $\mathrm{H}$ atom abstraction at the primary site,

$$
C-C-\stackrel{C}{C}-C-C
$$

The $\beta$-decomposition of this radical then produces $\mathrm{C}_{2} \mathrm{H}_{4}, \mathrm{OH}$, and methyl-ethyl ketone via very straightforward application of the principles of this reaction class. When the reaction mechanism for this fuel was assembled, since methyl-ethyl ketone had not been studied in the past, it was not included in the base kinetic reaction mechanism, so the $\beta$ decomposition reaction for the above sequence was forced to produce propionaldehyde rather than methyl-ethyl ketone, assuming that the overall rate of reaction would not be affected by this substitution. The success of the model in predicting the correct critical 
compression ratio confirms the validity of this assumption, but the inability of the model to predict any methyl-ethyl ketone indicates that there are still some refinements possible in the model. Similar analyses of most of the other differences between predicted and measured species concentrations are able to resolve the differences.

The great majority of the experimentally measured species concentrations can be explained by considering the major reaction paths to be expected. For example, the ratio of acetaldehyde to acetone varies in the experiments from nearly all acetaldehyde in the cases of n-hexane (Table V) and 3-methyl pentane (Table VII), to approximately equal levels for 2-methyl pentane (Table VI), 2,2-dimethyl butane (Table VIII) and 2,3dimethyl butane (Table IX). For the most part, these trends are exaggerated in the computed results, although the same trends from one fuel to another are correctly reproduced. For many of the smaller intermediate species, there are a variety of kinetic paths which can produce the same product species, and some of these reaction paths may be included while others may be omitted or replaced by approximate product species distributions from reactions where the products are not known.

The overall computed results were found to be sensitive to many of the families of elementary reactions encountered in the oxidation path, including addition of molecular oxygen to the large alkyl radicals, the isomerization of the alkylperoxy radicals, decomposition of QOOH species to different families of products which lead to chain propagation, addition of molecular oxygen to $\mathrm{QOOH}$, and the second class of radical isomerization reactions. In particular, the importance of accurate thermochemical data was also found to be essential in the models, and the incorporation of the work of Bozzelli was extremely valuable. Our previous conclusions [sae] regarding the major factors responsible for the observed dependence of octane rating and knock tendency on fuel molecule size and structure have been reinforced by the present study. The branched fuels are generally slower to ignite than the more linear molecules, and the most important reasons involve the increased ring strain energy associated with more compact fuel structure, as well as the higher percentage of strong primary $\mathrm{C}-\mathrm{H}$ bonds in the branched fuel molecules. The present study provides a particularly well focused forum for testing these theories, since all five isomers differ exclusively in their molecular structure, and the detailed reaction mechanisms as revised for this work are able to reproduce the observed behavior quite accurately.

\section{SUMMARY}

Autoignition of the isomers of hexane has been studied experimentally using motored engine techniques and computationally using a detailed chemical kinetics model. Relative ordering of the hexanes, with respect to their critical compression ratios for autoignition and the major intermediate chemical species produced, are all well reproduced by the kinetic model. In addition, the appearance of negative temperature coefficient phenomena was observed for three of the hexane isomers, and this behavior has been related to the more general problem of fuel octane sensitivity. The next level of model validations and testing should involve studies of the autoignition of mixtures of fuels, and of mixtures of hexane isomers in particular to 
examine the non-linear coupling of different types of reaction sequences. In addition, extension of the same modeling approach to larger and more complex hydrocarbon fuels is also warranted in order to further examine the details of the reactions mechanisms and the generality of the approach. Finally, kinetic studies of hexane isomer oxidation under other experimental conditions would help to further refine the details of the kinetic reaction mechanisms, and such studies are in progress.

\section{ACKNOWLEDGMENTS}

The authors are pleased to acknowledge the contributions of Professor Joseph Bozzelli of the New Jersey Institute of Technology and Dr. Nick Marinov of LLNL for their insights and suggestions in this work. Additional contributions over the extended period of this work by members of the DOE Engine Knock Working Group are also appreciated. This work was supported in part by the U.S. Department of Energy, Office of Transportation Technologies and the Office of Basic Energy Sciences, Chemical Sciences Branch, and carried out under the auspices of the U.S. Department of Energy by the Lawrence Livermore National Laboratory under contract W-7405-ENG-48. 


\section{REFERENCES}

1. Lovell, W. G., "Knocking Characteristics of Hydrocarbons," Ind. Eng. Chem. 40, 2388 (1948).

2. Vermeersch, M. L., Held, T. J., Stein, Y. S., and Dryer, F. L., SAE Trans. 100, 645 (1991).

3. Cernansky, N. P., Green, R. M., Pitz, W. J., and Westbrook, C. K., "Chemistry of Fuel Oxidation Preceding End-Gas Autoignition," Combust. Sci. Technol. 50, 3 (1986).

4. Lignola, P. G., DiMaio, F. P., Marzocchella, A., Mercogliano, R., and Reverchon, E., Twenty-Second Symposium (International) on Combustion, p. 1625, The Combustion Institute, Pittsburgh, 1989.

5. Chakir, A., Bellimam, M., Boettner, J. C., and Cathonnet, M., Int. J. Chem. Kinet. 24, 385 (1992).

6. Cavaliere, A., Ciajolo, A., D'Anna, A., Mercogliano, R., and Ragucci, R., Combust. Flame 93, 279 (1993).

7. Dagaut, P., Reullon, M., and Cathonnet, M., Combust. Sci. Tech. 95, 233 (1994).

8. Minetti, R., Carlier, M. Rivaucour, M. Therssen, E., and Sochet, L. R., Combust. Flame, in press (1995).

9. Griffiths, J. F., Hughes, K. J., Schreiber, M. and Poppe, C., Combust. Flame 99, 533 (1994).

10. Westbrook, C. K., Pitz, W. J., and Leppard, W. R.; "The Autoignition Chemistry of Paraffinic Fuels and Pro-Knock and Anti-Knock Additives: A Detailed Chemical Kinetic Study," SAE paper SAE-912314 (1991).

11. Pitz, W. J., Westbrook, C. K., and Leppard, W. R., "Autoignition Chemistry of C4 Olefins Under Motored Engine Conditions: A Comparison of Experimental and Modeling Results," SAE paper SAE-912315 (1991).

12. Pollard, R. T., "Hydrocarbons," Ch. 2, Comprehensive Chemical Kinetics, vol. 17, Gas-Phase Combustion (C. H. Bamford and C. F. H. Tipper, eds.), Elsevier, New York (1977).

13. Leppard, W. R., "A Comparison of Olefin and Paraffin Autoignition Chemistries: A Motored-Engine Study," SAE paper SAE-892081 (1989).

14. Leppard, W. R., "The Chemical Origin of Fuel Octane Sensitivity," SAE paper SAE-902137 (1990).

15. Leppard, W. R., "The Autoignition Chemistries of Primary Reference Fuels, Olefin/Paraffin Binary Mixtures, and Non-Linear Octane Blending", SAE paper SAE-922325 (1992).

16. Lipari, F., and Swarin, S. J., "Determination of Formaldehyde and Other Aldehydes in Automobile Exhaust with an Improved 2,4Dinitrophenylhydrazine Method," J. Chromatog. 247, 297 (1982).

17. Perry, K. L., "A Gas Chromatographic Technique for the Analysis of Fuel Vapor Containing Oxygenates," J. Chrom. Sci. 28, 624 (1990).

18. Lund, C. M., "HCT - A General Computer Program for Calculating TimeDependent Phenomena Involving One-Dimensional Hydrodynamics, Transport, and Detailed Chemical Kinetics," Lawrence Livermore National Laboratory report UCRL-52504 (1978). 
19. Kaiser, E. W., Westbrook, C. K., and Pitz, W. J., "Acetaldehyde Oxidation in the Negative Temperature Coefficient Regime: Experimental and Modeling Results," Int. J. Chem. Kinet. 18, 655 (1986).

20. Westbrook, C. K., Warnatz, J., and Pitz, W. J., "A. Detailed Chemical Kinetic Reaction Mechanism for the Oxidation of iso-Octane and n-Heptane over an Extended Temperature Range and its Application to Analysis of Engine Knock," Twenty-Second Symposium (International) on Combustion, p. 893, The Combustion Institute, Pittsburgh, 1988.

21. Green, R. M., Cernansky, N. P., Pitz, W. J., and Westbrook, C. K., "The Role of Low Temperature Chemistry in the Autoignition of n-Butane," SAE paper SAE872108 (1987).

22. Heywood, J. B., "Internal Combustion Engine Fundamentals," McGraw-Hill Publishing Co., New York, 1988.

23. Westbrook, C. K., and Dryer, F. L., "Chemical Kinetics and Modeling of Combustion Processes," Eighteenth Symposium (International) on Combustion, p. 749, The Combustion Institute, Pittsburgh, 1981.

24. Westbrook, C. K., and Dryer, F. L., "Chemical Kinetic Modeling of Hydrocarbon Combustion," Prog. Energy Comb. Sci. 10, 1 (1984).

25. Benson, S. W., "Thermochemical Kinetics," Wiley, New York, 1976.

26. Lay, T., and Bozzelli, J.W., Eastern States Meeting of the Combustion Institute, paper no. 100 (1993).

27. Ritter, E. R., and Bozzelli, J. W., "THERM: Thermodynamic Property Estimation for Radicals and Molecules," Int. J. Chem. Kinet. 23, 767 (1991).

28. Ranzi, E., Sogaro, A., Gaffuri, P., Pennati, G., Westbrook, C. K., and Pitz, W. J., Combust. Flame 99, 201 (1994).

29. Ranzi, E., Gaffuri, P., Faravelli, T., and Dagaut, P., "A Wide Range Modeling Study of n-heptane Oxidation," Combust. Flame, in press (1995).

30. Curran, H. J., Gaffuri, P., Pitz, W. J., and Westbrook, C. K., in preparation (1995). 


\section{FIGURE CAPTIONS}

1. Experimental results, showing $\mathrm{CO}$ exhaust concentrations as functions of compression ratio for the five isomeric hexanes. For compression ratios slightly greater than the last point plotted for each fuel, autoignition was observed.

2. Typical GC results for hydrocarbon species with n-hexane fuel.

3. Typical GC results for oxygenated hydrocarbon species with $n$-hexane fuel.

4. Typical GC results for hydrocarbon species with 3-methyl pentane fuel.

5. Typical GC results for oxygenated hydrocarbon species with 3-methyl pentane fuel.

6. Typical GC results for hydrocarbon species with 2,2-dimethyl pentane fuel.

7. Typical GC results for oxygenated hydrocarbon species with 2,2-dimethyl pentane fuel.

8. Computed and experimental pressure histories in the absence of chemical reaction for $\mathrm{CR}=6.63$.

9. Computed results, showing predicted $\mathrm{CO}$ exhaust concentrations as functions of compression ratio for the isomeric hexanes, except n-hexane which is not included. At compression ratios slightly greater than the last point plotted, the model predicted autoignition.

10. Comparison of computed and experimental exhaust $\mathrm{CO}$ concentrations, using the same scale for compression ratio. Note the $\mathrm{CO}$ concentration scales are not the same in the two parts of the figure. 


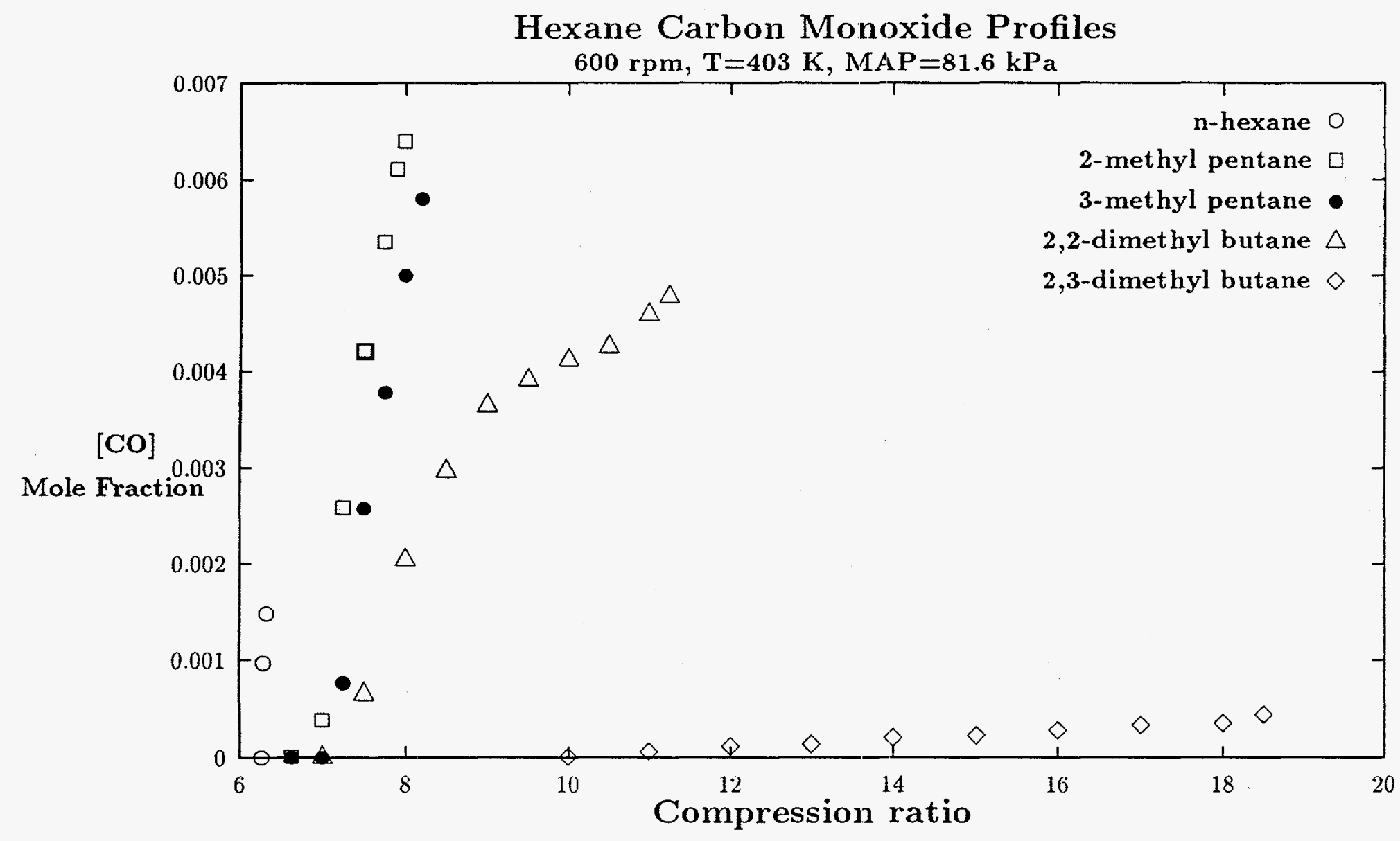

Fig 1 


\section{n-HEXANE - HYDROCARBONS}

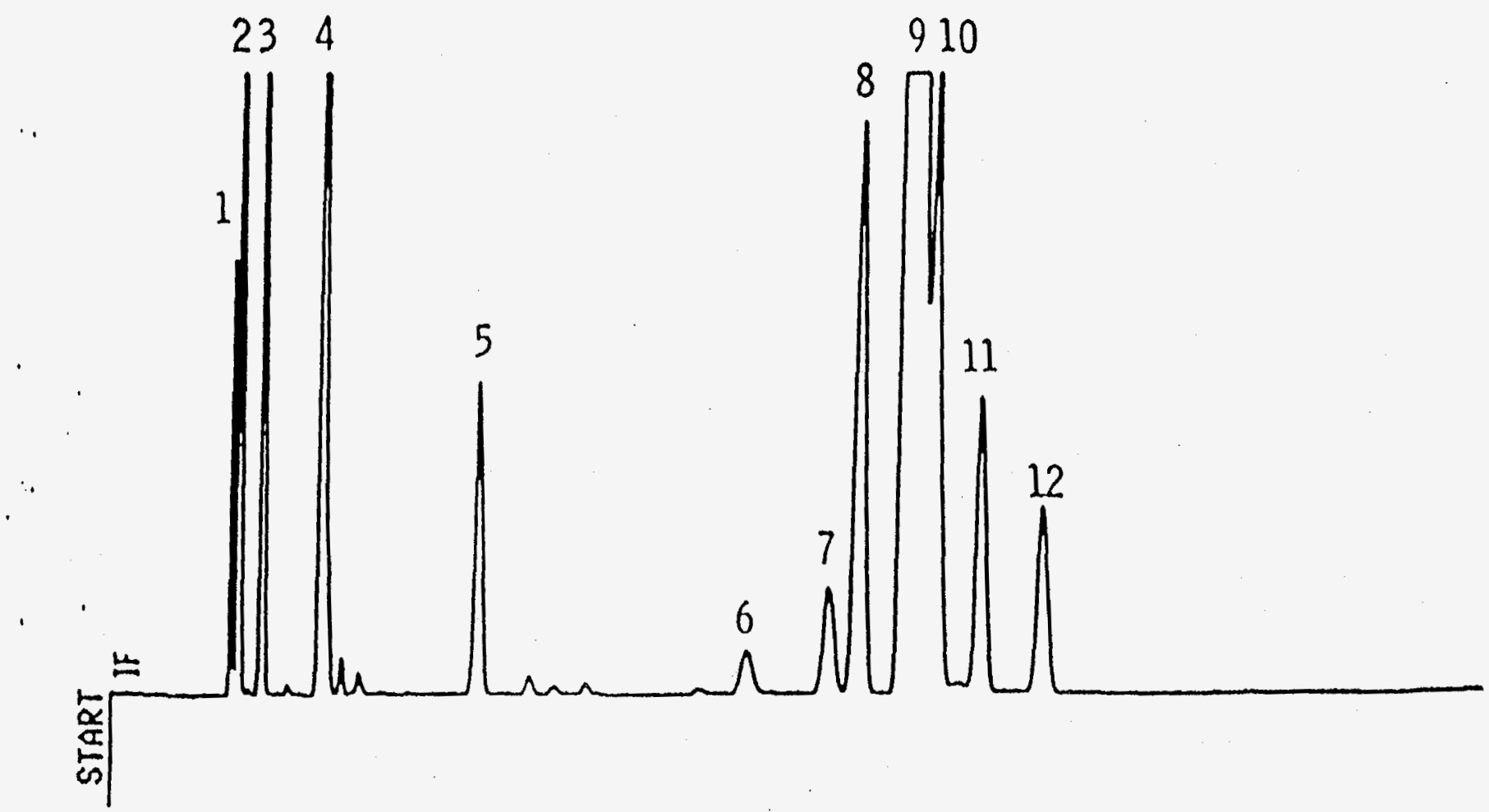

1. Methane

2. Ethylene

3. Propylene

4. 1-Butene
5. 1-Pentene

6. 2,3-Dimethyl Butane*

7. 3-Methyl Pentane**

8. 1-Hexene

* contaminant

** In fuel
9. Fuel $+t-3-$ Hexene

10. t-2-Hexene

11. c-2-Hexene

12. 2,3-Dimethyl-2-Butene?* * 


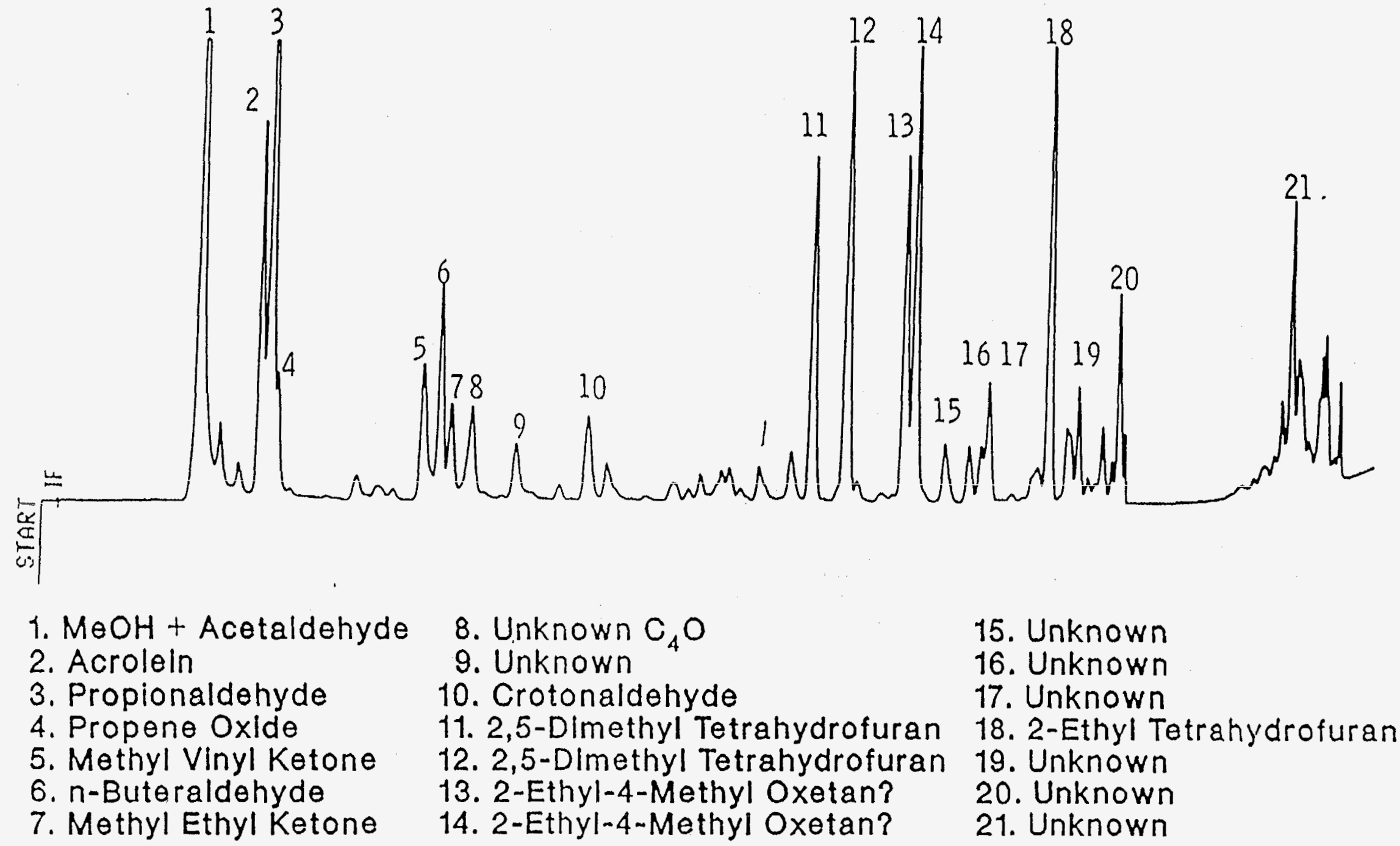




\section{3-METHYLPENTANE - HYDROCARBON SPECIES}

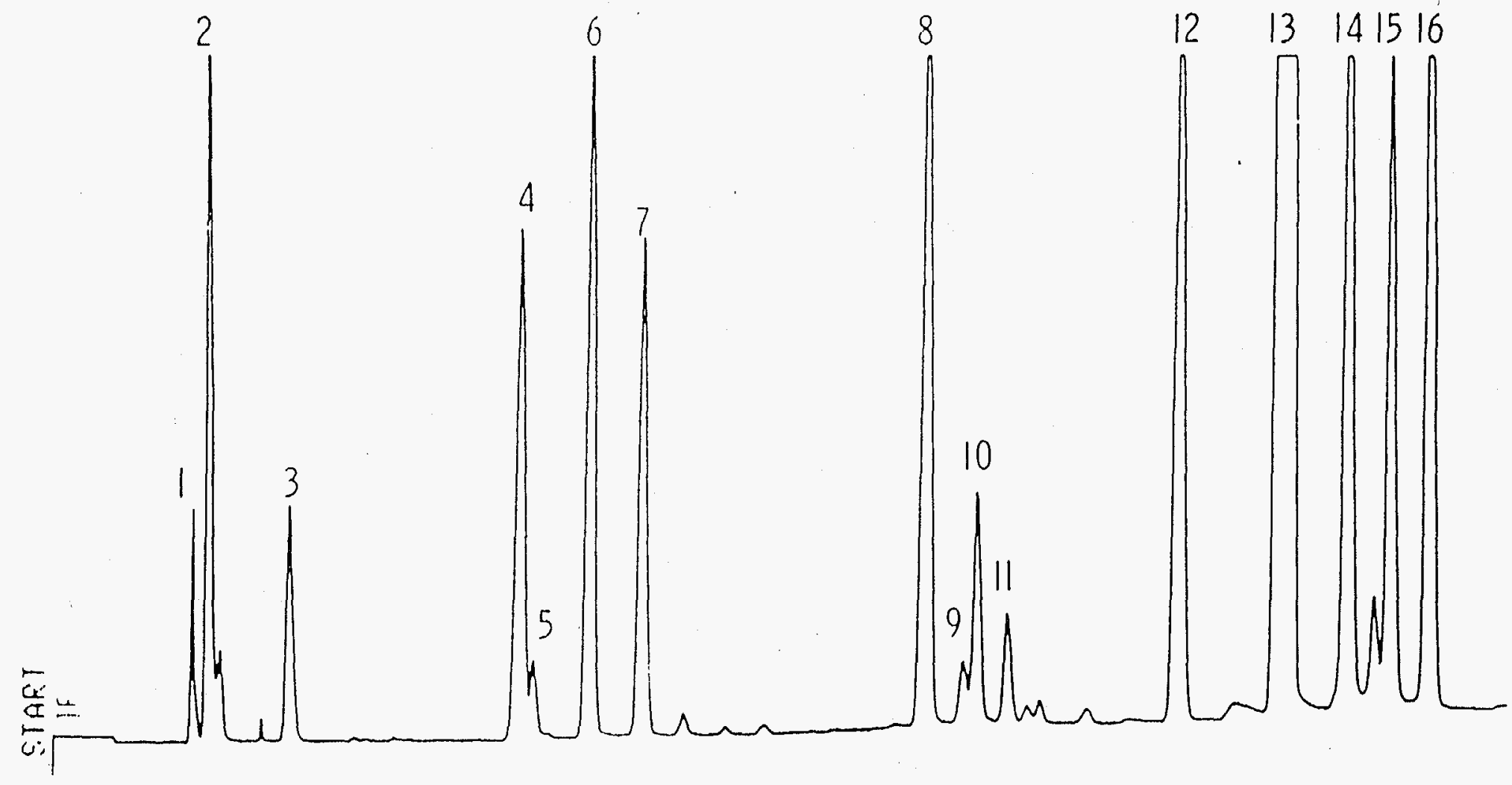

1- Methane

2- Ethene

3- Propene

4-1-Butene

5 - 1,3-Butadiene

6 - $t$-2-Butene
7-c-2-Butene

8-2-Methyl-1-Butene

9 - Isoprene

10-c-2-Pentene

11- t-2-Pentene

12-3-methyl-1-Pentene
13- fuel

14-2-Ethyl-1-Butene

15-3-Methyl-2-Pentene 16-3-Methyl-2-Pentene 


\section{3-METHYLPENTANE - OXYGENATED SPECIES}

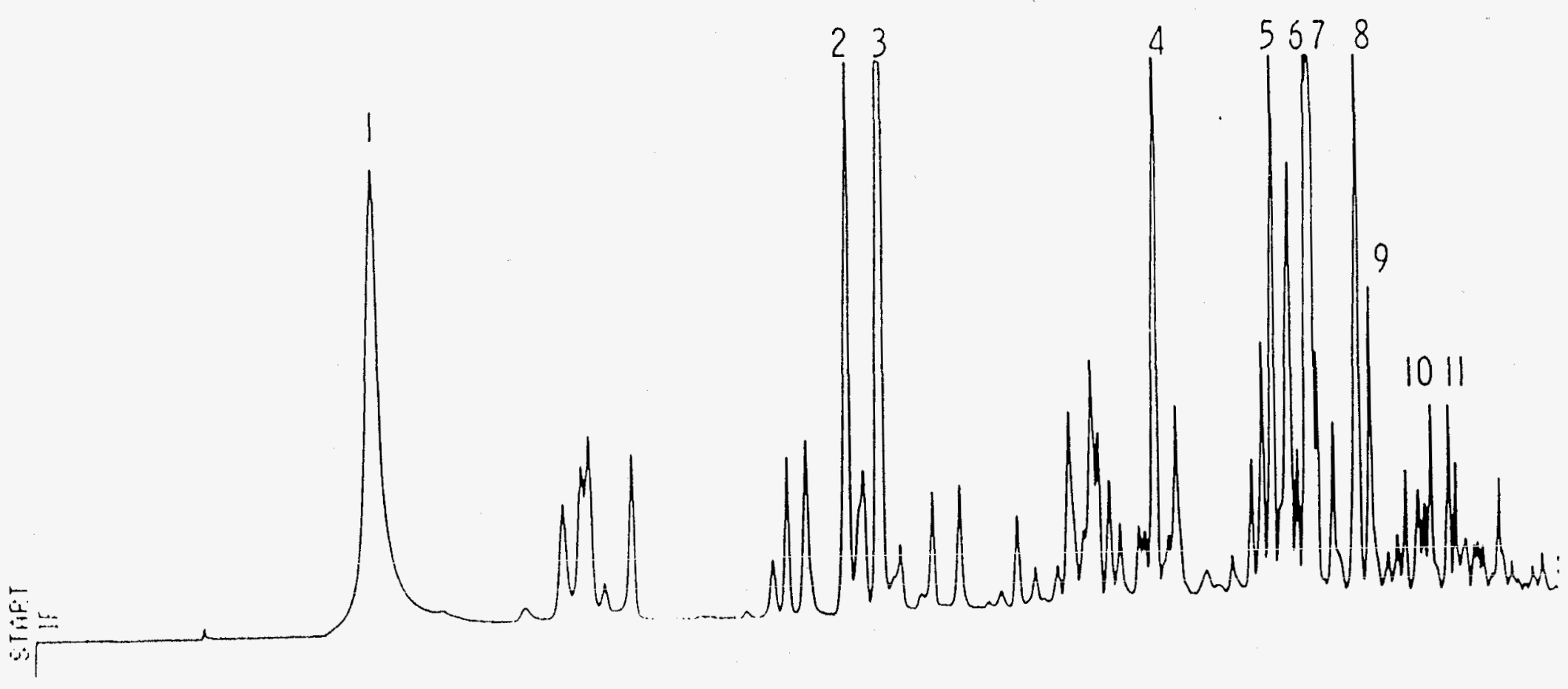

1-Acetaldehyde

2- Methyl Vinyl Ketone

3- Methyl Ethyl Ketone

4- 2,3,4-Trimethyl Oxetane
5-2,3,4-Trimethyl Oxetane

6-2,3-Dimethyl Tetrahydrofuran

7-2-Methyl-2-Ethyl Oxetane

8- 2-Methyl-3-Ethyl Oxetane
9-2,3-Dimethyl Tetrahydrofuran 10-2-Methyl-3-Ethyl Oxetane 11-3-Ethyl Tetrahydrofuran 
$\stackrel{0}{E}$

苛昌

$\infty$

$\div \pm$

$\frac{1}{2} \frac{1}{1}$

(1)

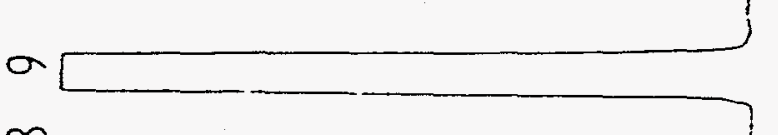

()

$\infty$

ㄴ.

C)

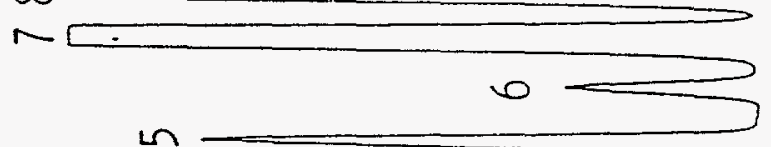

2

$\frac{0}{0}$

0

동

0
$I$

1

L

$\frac{1}{2}$

D

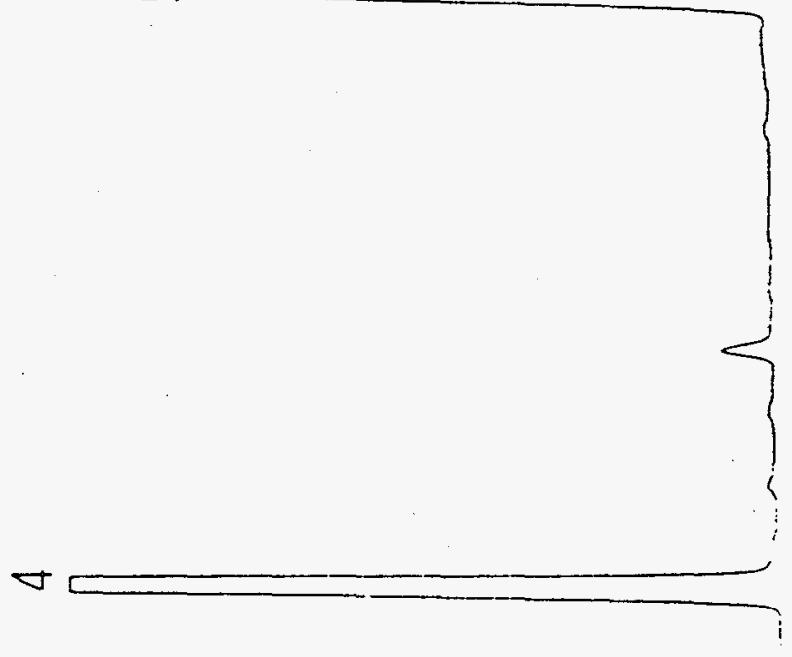

$\Sigma \sim$

(1) $\frac{1}{2}$

$E \approx$

0

$\infty \sum 0$

mंu

N' ó

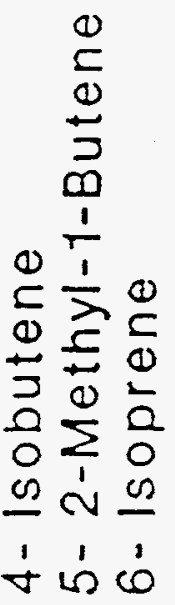

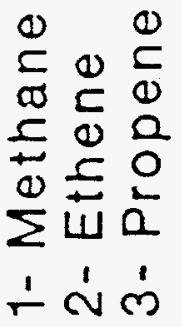

$F_{1}=1$ 


\section{2,2-DIMETHYLBUTANE - OXYGENATED SPECIES}

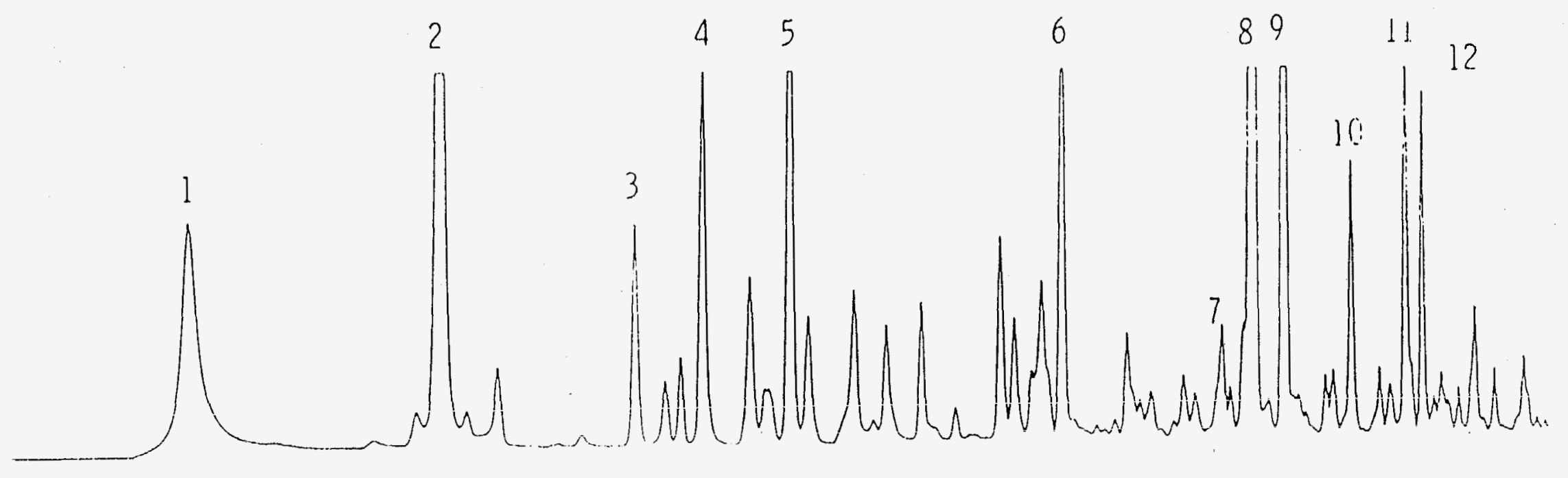

1- Acetaldehyde

2- Acetone

3- Isobutene Oxide

4- Methacroleln
5- Fuel interference

6- C5 Carbonyl

7-3,3-Dlmethyl-1,2-Epoxybutane

8-2,3,3-Trlmethyl Oxetane
9-3,3-Dimethyl Tetrahydrofuran 10- $u / k$ Ester

11-3,3-Methylethyl Oxetane 12- $\mathrm{u} / \mathrm{k}$ Ester 


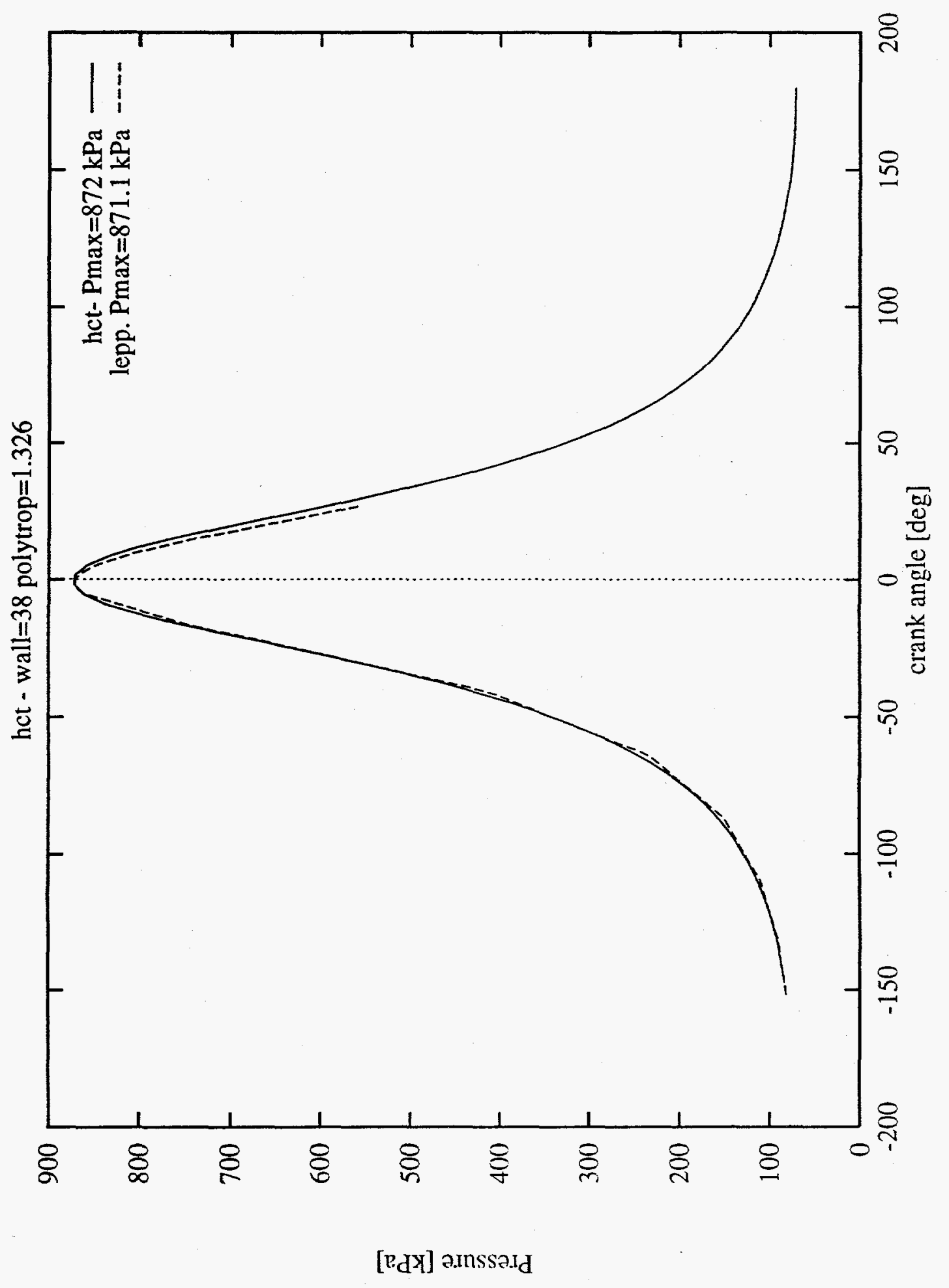

$f:=8$ 


\section{Hexane Carbon Monoxide Profiles}

$600 \mathrm{rpm}, \mathrm{T}=403 \mathrm{~K}, \mathrm{MAP}=81.6 \mathrm{kPa}$

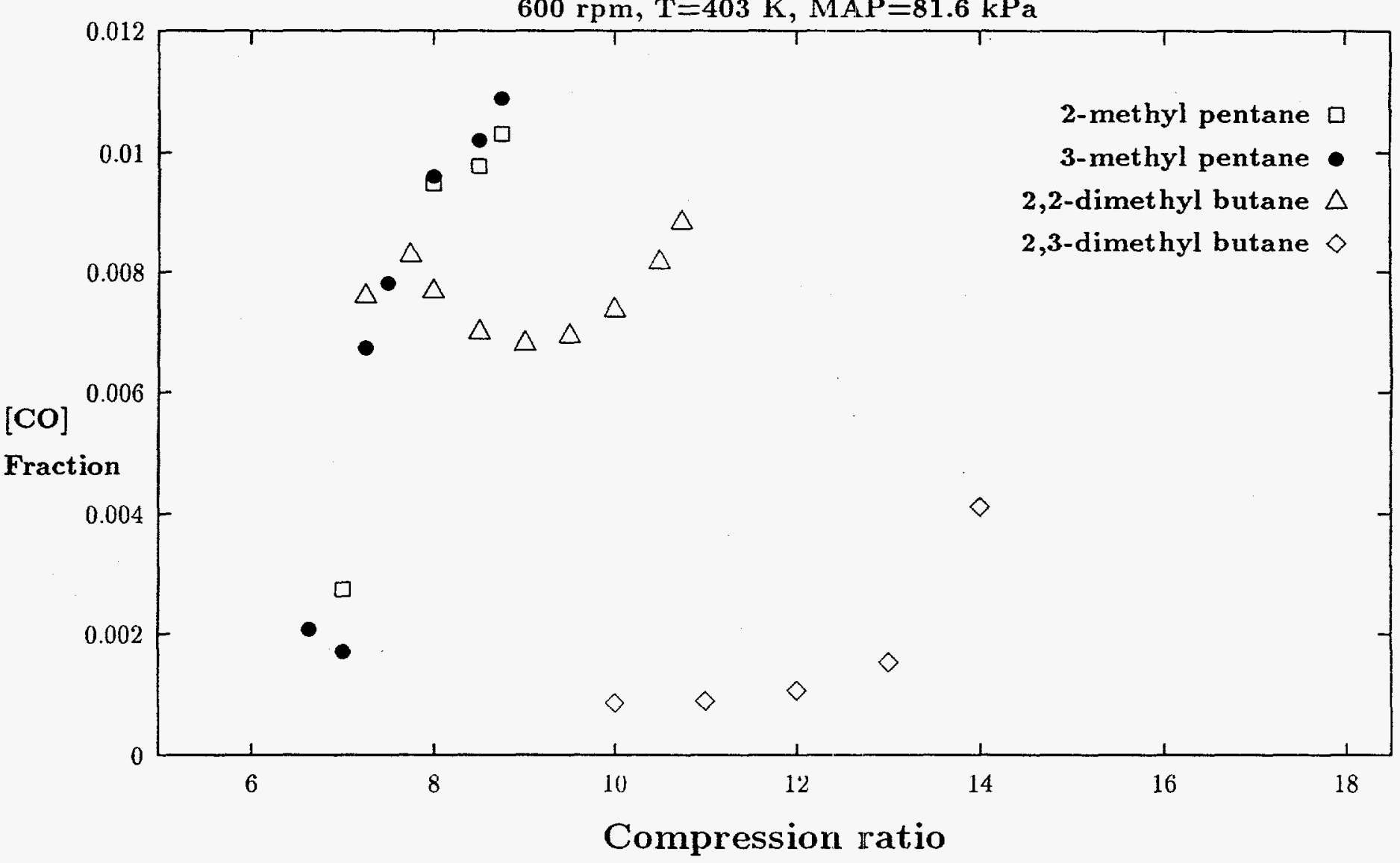

fig 9 

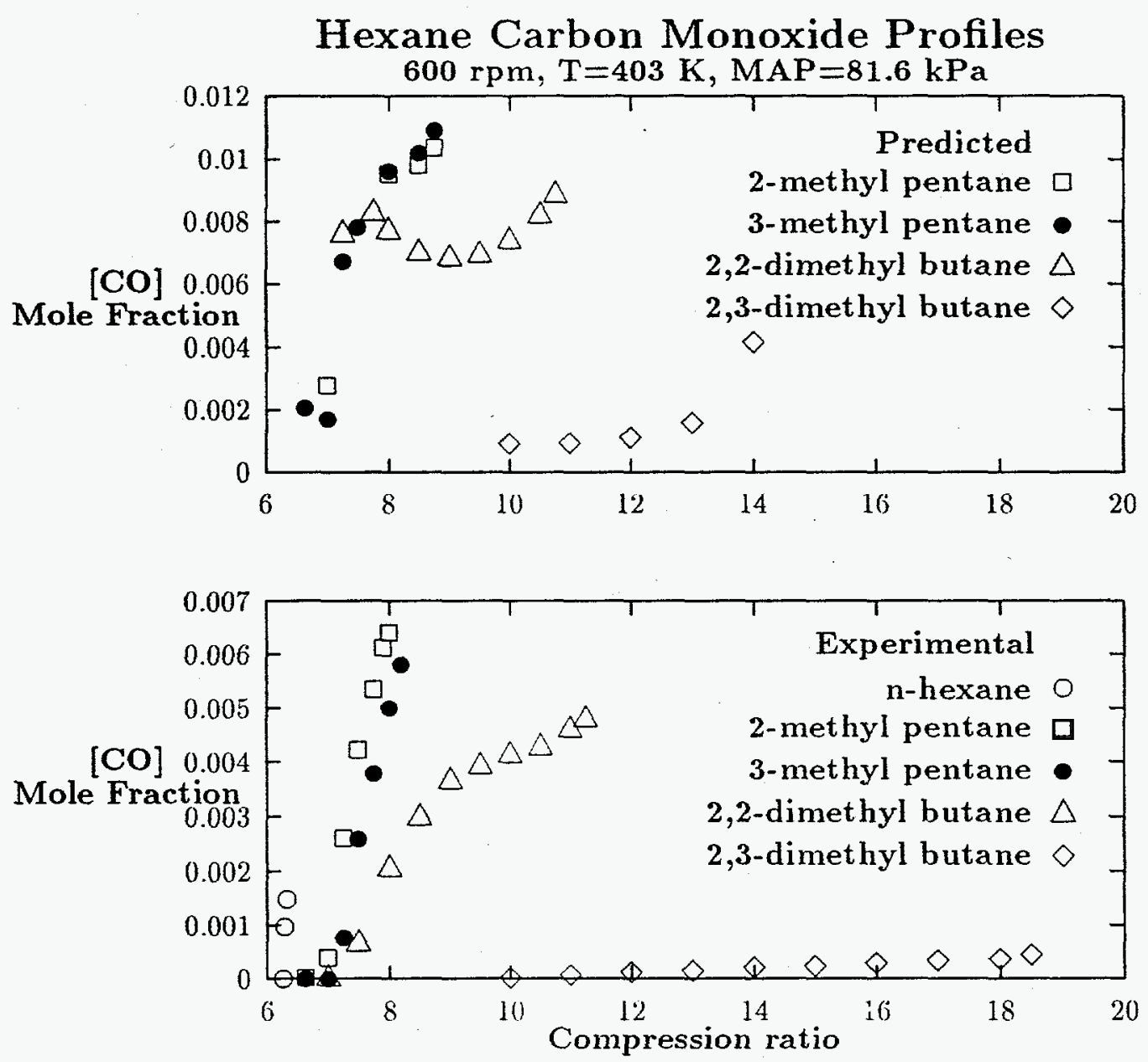

Fis 10 